\title{
Investigation of Drift Gas Selectivity in High Resolution Ion Mobility Spectrometry with Mass Spectrometry Detection
}

\author{
Laura M. Matz and Herbert H. Hill, Jr. \\ Department of Chemistry, Washington State University, Pullman, Washington, USA \\ Luther W. Beegle and Isik Kanik \\ Jet Propulsion Laboratory, California Institute of Technology, Pasadena, California, USA
}

\begin{abstract}
Recent studies in electrospray ionization (ESI)/ion mobility spectrometry (IMS) have focussed on employing different drift gases to alter separation efficiency for some molecules. This study investigates four structurally similar classes of molecules (cocaine and metabolites, amphetamines, benzodiazepines, and small peptides) to determine the effect of structure on relative mobility changes in four drift gases (helium, nitrogen, argon, carbon dioxide). Collision cross sections were plotted against drift gas polarizability and a linear relationship was found for the nineteen compounds evaluated in the study. Based on the reduced mobility database, all nineteen compounds could be separated in one of the four drift gases, however, the drift gas that provided optimal separation was specific for the two compounds. (J Am Soc Mass Spectrom 2002, 13, 300-307) (c) 2002 American Society for Mass Spectrometry
\end{abstract}

$\mathrm{I}$ on mobility spectrometry (IMS) has become an important analytical separation technique because of recent advances in the field, specifically the incorporation of electrospray ionization (ESI) [1] and matrix assisted laser desorption ionization (MALDI) [2] sources to IMS and improvements in analytical resolution [3]. Traditionally considered a low-resolution technique, increases in IMS resolution have enabled the operation of IMS at separation efficiencies exceeding those of liquid chromatography (LC) and rivaling those of gas chromatography (GC) [3e]. The combination of ESI with high-resolution IMS systems has been shown to be an important separation technique for a wide range of applications (drugs [4], chemical warfare agents [5], peptides [3d, 6], and proteins [7]).

However, unlike chromatographic methods which alter selectivity $(\alpha)$ by varying the mobile and stationary phases, it is difficult to change the IMS selectivity. In IMS, ions are separated based on their mobilities in a buffer gas under the influence of an electric field [8]. Separations are based on the size and charge of the ions and their interaction with the buffer gas (also termed drift gas). Altering the identity of the buffer gas (both the polarizability and mass) affects the ion-neutral interaction and is a way to manipulate the IMS separation capabilities. The IMS selectivity can also be

Published online January 25, 2002

Address reprint requests to Dr. H. H. Hill, Jr., Department of Chemistry, Washington State University, P.O. Box 644630, Pullman, WA 99164-4630. E-mail: hhhill@wsu.edu

changed by operation in the high field regime (determined by the buffer gas, the electric field, the drift tube pressure, and the ion of interest) where an ion's mobility varies with the electric field [9].

Surprisingly, there has been very little IMS research employing varied drift gases, especially to alter the resolution of two compounds. Both nitrogen and air have been the most commonly used gases for analytical applications [10] and helium has been used for more structural experiments in which theoretical modeling was compared with experimental data [7]. The theory of using different drift gases was theoretically investigated 25 years ago, with little work since then [11]. In 1976, an investigation employing $\mathrm{CO}_{2}$ for a drift gas was evaluated, but the study was not successful due to cluster formation at low drift tube temperatures [12]. Operation of drift tubes at higher temperatures was found to enable analyte separations in $\mathrm{CO}_{2}[13,14]$. A handful of other papers have employed novel drift gases including sulfur hexafluoride [15], ammonia [16], and carbon tetrafluoride [17].

In IMS, an ion's mobility (K) is measured and is defined as the average velocity of the ion divided by the electric field (E) applied to the drift region. The mobility value is used as the identification tool for an ion. However, more fundamental information regarding the ions and their collision with the drift gas can be derived from the mobility. Based on Eq 1, the mobility can be related to the average ion-neutral collision cross section $\left(\Omega^{(1,1)}\right)[11]$ : 


$$
\mathrm{K}=\frac{3 q}{16 N}\left(\frac{2 \Pi}{\mu k T}\right)^{1 / 2}\left(\frac{1}{\Omega^{(1,1)}}\right)
$$

where $q$ is the charge on the ion, $N$ is the number density of the drift gas, $\mu$ is the reduced mass, $k$ is Boltzmann's constant, and $T$ is the effective temperature. Different levels of theory have been applied to relate fundamental characteristics of the ion-neutral collisions. Researchers would like to predict the collision cross sections/mobilities for ions in a given drift gas and also, to compare the measured collision cross sections with the calculated collision cross sections generated from molecular modeling simulations. However, this has proven to be a difficult task due to the complexity of the mobility experiment.

For comparison between computer modeled structures and experimental collision cross sections, helium is typically employed as the drift gas because it is a small and weakly interacting drift gas, providing the simplest gas to derive a theoretical understanding of the interaction between an ion and the gas [18-20]. Four detailed studies have evaluated the effect of several drift gases on the separation capabilities of IMS systems [21-24]. Karpas and Berant showed that based on IMS theory (assuming a 12,4 hard-core potential), the mobilities of a series of aliphatic amines could be predicted, specifically for the drift gas [22]. Based on these theoretical curve fits, the predominating interactions of the ion-neutral collision were determined for six drift gases [22]. Asbury and Hill showed that by employing a less rigorous model (assuming the ion and neutral molecules are two rigid spheres), they could estimate the ionic radii for several compounds in four drift gases [23]. They found an empirical linear correlation between the drift gas polarizability and calculated ion radii, showing that ions with different structures could be separated in certain drift gases. This relationship was then used to determine the drift gas that would enable optimal separation.

The theoretical studies of Karpas et al. proved that for a series of similar compounds, the mobilities in drift gases could be predicted [22], and the experimental studies of Asbury and Hill proved that the separation of two unresolved compounds in one gas could be resolved by changing the drift gas [23]. However, it is still unclear how to predict the separation capabilities of different analytes in different drift gases. In this study, several similar drug classes (amphetamines, cocaine and metabolites, and benzodiazepines) and small peptides were evaluated in four different drift gases. The objectives of this study were to begin accruing a database of mobility values for some important classes of compounds in different drift gases and to specifically determine the capabilities of IMS for separating the three drug classes and small peptides. In this study, any and all interactions between the drift gas and the ion are accounted for in the calculations and are related empirically to the drift gas polarizability similar to the ap- proach by Asbury and Hill. This method elucidates any relationships between the mobilities for similar compounds when measured in different drift gases.

\section{Experimental}

\section{Reagents and Chemicals}

All solvents used for standard preparation and the ESI mobile phase (water, methanol, and acetic acid) were reagent grade and were purchased from J. T. Baker (Phillipsburg, NJ). All drug standards (cocaine COC, benzoylecgonine $\mathrm{BE}$, cocaethylene $\mathrm{CE}$, ecgonine methyl ester EME, amphetamine AM, methamphetamine MA, ethylamphetamine EA, 3,4-methylenedioxy amphetamine MDA, 3,4-methylenedioxy methamphetamine MDMA, 3,4-methylenedioxy ethylamphetamine MDEA, diazepam, oxazepam, lorazepam, chlordiazepoxide, and bromazepam) were acquired from Radian International (Austin, TX) in concentrations of $1 \mathrm{mg} / \mathrm{ml}$ standards. All standards were diluted and analyzed at concentrations of approximately $10 \mu \mathrm{g} / \mathrm{ml}$ for the drug standards and $100 \mu \mathrm{g} / \mathrm{ml}$ for the peptide standards. The six peptides (GK, AK, VK, MK, GHK, and LR) were obtained from Sigma (St. Louis, $\mathrm{MO}$ ) and diluted in the ESI mobile phase solvent.

\section{Instrumentation}

The ESI/IMS/MS instrument that was utilized for all experiments was constructed at Washington State University. The ESI was a water-cooled source that has been described previously [1d]. The IMS/MS instrument was discussed in the literature [3c] and recent modifications to the instrument have been further documented [3e].

The electrospray solvent consisted of $47.5 \%$ water/ $47.5 \%$ methanol with $5 \%$ acetic acid. A Brownlee Labs (Santa Clara, CA) dual-piston syringe pump was employed for all experiments and the ESI flow rate was maintained at $5 \mu \mathrm{l} / \mathrm{min}$. The electrospray needle was maintained at $13.0 \mathrm{kV}(12.0 \mathrm{kV}$ for helium), resulting in a difference of $3.5 \mathrm{kV}$ ( $3.0 \mathrm{kV}$ for helium) between the needle and the target screen (first ring of the drift region).

The IMS instrument consisted of two regions; a desolvation region $(7.2 \mathrm{~cm}$ in length) and a drift region $(22.5 \mathrm{~cm}$ in length). Both regions were operated at $250{ }^{\circ} \mathrm{C}$ and atmospheric pressure (690-700 torr, Pullman, WA). The IMS was always operated in positive mode and potentials of $9 \mathrm{kV}(\mathrm{He})$ and $9.5 \mathrm{kV}\left(\mathrm{N}_{2}, \mathrm{Ar}\right.$, and $\mathrm{CO}_{2}$ ) were applied to the drift tube. A counterflow of preheated drift gas was introduced at the end of the drift region with flow rates of $1.2 \mathrm{~L} / \mathrm{min}\left(\mathrm{N}_{2}, \mathrm{Ar}\right.$, and $\mathrm{CO}_{2}$ ) and $1.6 \mathrm{~L} / \mathrm{min}$ for helium.

The IMS was coupled to a quadrupole MS via a 40 $\mu \mathrm{m}$ pinhole. The MS system had a mass range of 0-4000 a $\mu$ and was purchased from ABB Extrel (Pittsburgh, PA, Model 150-QC). There were six Einzel lenses 
Table 1. Molecular weight, polarizability values, and calculated radii for four drift gases employed in the study

\begin{tabular}{lcc}
\hline Drift gas & $\begin{array}{c}\text { Molecular } \\
\text { weight }\end{array}$ & $\begin{array}{c}\text { Polarizability } \\
\left(10^{-24} \mathrm{~cm}^{3}\right)\end{array}$ \\
\hline \hline Helium & 4 & 0.205 \\
Argon & 40 & 1.641 \\
Nitrogen & 28 & 1.740 \\
Carbon Dioxide & 44 & 2.911 \\
\hline
\end{tabular}

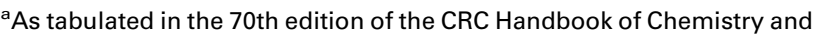
Physics.

between the IMS and the quadrupole and were operated with voltages as follows: $+8.0 \mathrm{~V}$ (pinhole), $-42.8 \mathrm{~V}$ (screen), $-116.3 \mathrm{~V}$ (first einzel element), $-34.5 \mathrm{~V}$ (second einzel element), $-17.3 \mathrm{~V}$ (third einzel element), and $-50.9 \mathrm{~V}$ (ELFS plate). The electron multiplier was operated at $1.7 \mathrm{kV}$ for the solvent spectra. The dynode was operated at $-5.0 \mathrm{kV}$ and the quadrupole rods were biased at $-20.8 \mathrm{~V}$.

IMS data acquisition was performed with a Labview (National Instruments, Houston, TX) data acquisition card and Labview 5.0 software which was modified at Washington State University. The gating electronics were controlled by the Labview software and the electronics have been described previously [1d].

\section{Calculations}

The reduced mobility values reported were calculated based on the following equation:

$$
\mathrm{K}_{\mathrm{o}}=\left(\frac{L^{2}}{V * t_{d}}\right)\left(\frac{273}{T}\right)\left(\frac{P}{760}\right)
$$

where $L$ is the drift region length $(22.5 \mathrm{~cm}), V$ is the drift voltage $(7900 \mathrm{~V}), T$ is the effective temperature in the drift region (523 Kelvin), and $P$ is the pressure in the drift region ( $\sim 690-700$ torr in Pullman, WA).

The collision cross section for the analytes in each drift gas were calculated according to equation 1 . The values for the estimated neutral gas polarizability values are listed in Table 1.

\section{Results and Discussion}

\section{Drift Gas Polarizability}

The previous study by Asbury and Hill found a linear correlation between the gas polarizability and the ionic radii (the drift gas and ion were both considered to be rigid spheres) [23]. These evaluations were performed for some simple molecules (aniline compounds) and peptides. The calculated ionic radii varied in different drift gases and were correlated linearly with the drift gas polarizability. This study found that the slopes obtained from the linear correlations indicated differences in structure and could be employed to optimize the separation of two compounds. The slopes were a) Structure of Cocaine and 3 Metabolites

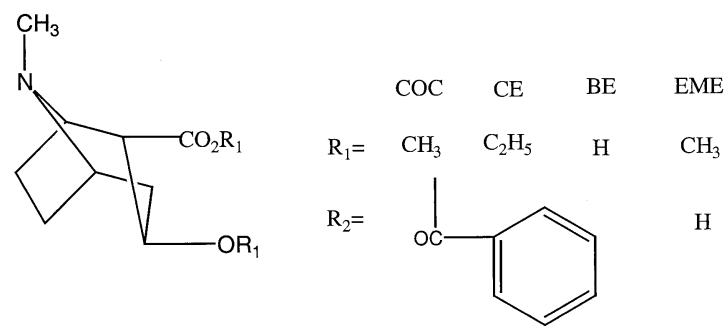

b) Structure of Amphetamines
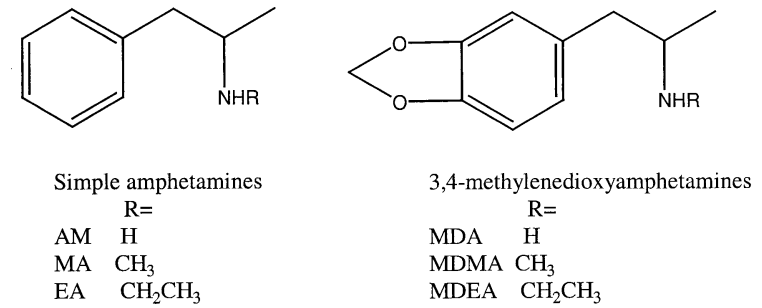

Scheme 1 Structural diagrams of (a) cocaine/metabolites and (b) amphetamines.

interpreted to be a measure of charge density on the ion where steeper slopes (seen for less massive radii) indicated greater ion charge density and hence more interaction due to drift gas polarizability. The ability to understand these slopes would enable the analyst to predict separations without experimentally evaluating the compounds in each drift gas. In this study, four classes of molecules (cocaine/metabolites, amphetamines, benzodiazepines, and peptides) were evaluated for similar linearity relationships. In this study, the relationship between the collision cross section (instead of ionic radii) and the drift gas polarizability were studied.

\section{Cocaine/Metabolites}

The structures of cocaine and three of its primary metabolites are shown in Scheme 1. As seen in Scheme 1, CE is the largest compound and EME is the smallest. $\mathrm{CE} /$ Cocaine and Cocaine/BE only differ by $14 \mathrm{a} \mu$. The ion mobility spectra for these four compounds were obtained in the four drift gases employed in this study (helium, nitrogen, argon, and carbon dioxide). The empirical correlation between the collision cross sections and drift gas polarizability are shown in Figure 1. The collision cross sections were calculated from the experimentally measured drift times using Eq 3. In general, increasing the ion mass (EME, BE, cocaine, and $\mathrm{CE}$ ) increased the ion collision cross section in a given gas. Also, similar to previous studies [20, 21], the largest $\mathrm{K}_{\mathrm{o}}$ and smallest collision cross sections (fastest drift time) values were observed in helium (the smallest drift gas) and the smallest $K_{o}$ values were observed in carbon dioxide (the largest drift gas). As shown in Scheme 1, the difference in the three compounds was the addition 


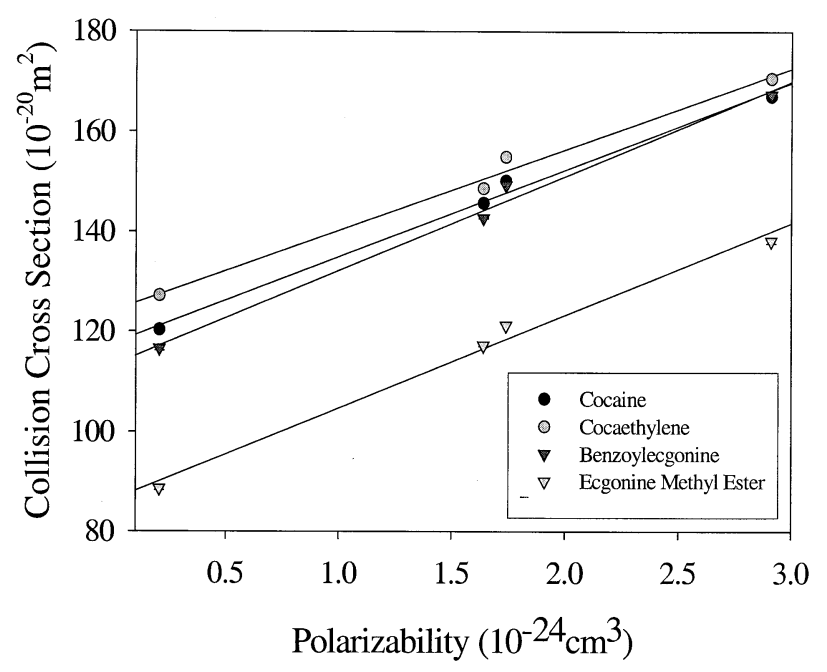

Figure 1. Calculated ion collision cross section as a function of drift gas polarizability. The graph shows the trends for cocaine and three metabolites (CE-cocaethylene, BE-benzoylecgonine, EME-ecgonine methyl ester).

of an alkyl group (CE ethyl, Cocaine methyl, and BE proton) at the ester functional group and was the only structural difference between these three compounds. Inspection of Figure 1 showed that the largest differences in collisional cross section for the three compounds were observed in helium drift gas and the smallest difference was obtained in carbon dioxide.

The previous study by Asbury and Hill found that the radii were not only dependent on the mass of the drift gas but also on the drift gas polarizability [23]. In their study, a linear increase in ionic radii with drift gas polarizability was found. This dependence on radii would also be apparent in the collision cross sections since the ionic size contribute largely to the ion/drift gas collision cross section. The relationship (collision cross section versus drift gas polarizability) in Figure 1 was found to be linear and the slope, intercept, and $\mathrm{R}^{2}$ values are reported in Table 2. For these four compounds, there was a linear correlation between polarizability and collision cross section and the best separation capability was obtained with helium, the smallest drift gas.

In order to predict drift gas relationships, it is important to determine what the slopes for very similar molecules indicate about the molecular structure. By comparing the collision cross section slope values in Table 2 , it was observed that the slope values decreased with increasing mass (BE, Cocaine, and $\mathrm{CE}$ ), the reason for the different separation capabilities for the drift gases seen in Figure 1. For these four compounds, the best separation was attained in helium and the least separation was attained with carbon dioxide as the drift gas.

\section{Amphetamines}

The second class of compounds that was studied consisted of six amphetamines and the structures are shown in Scheme $\mathbf{1 b}$ (two classes; simple amphet-
Table 2. Table of Linear Regression values the collision cross section values versus the drift gas polarizability for cocaine and three metabolites in four different drift gases

\begin{tabular}{lccc}
\hline Compound & $\begin{array}{c}\text { Slope } \\
(\Omega)\end{array}$ & $\begin{array}{c}\text { Intercept } \\
(\Omega)\end{array}$ & $\mathrm{R}^{2}(\Omega)$ \\
\hline \hline EME & 18.485 & 86.268 & 0.9891 \\
BE & 18.907 & 113.27 & 0.9899 \\
Cocaine & 17.397 & 117.56 & 0.9931 \\
CE & 16.166 & 124.09 & 0.9882 \\
EME* & 13.837 & 100.38 & 0.9997 \\
BE $^{*}$ & 22.947 & 111.85 & 0.9650 \\
Cocaine $^{*}$ & 18.132 & 119.55 & 0.9854 \\
CE* $^{*}$ & 18.232 & 123.5 & 0.9611 \\
\hline
\end{tabular}

* Indicates values for sodiated ions (linear regression did not include values for helium).

amines and methylenedioxy substituted amphetamines). Within each class, there were three compounds with different functional groups on the amine (expected protonation site) as follows; proton (AM and MDA), methyl (MA and MDMA) and ethyl (EA and MDEA). The trends in collision cross section (CCS) for these six compounds in the four drift gases are shown in Figure 2. By comparison of the CCS in the four drift gases, the CCS were related to the mass of the molecule in helium, nitrogen, and argon. The CCS values in carbon dioxide clearly split into the distinct classes; the simple and methylene dioxy amphetamines. Similar to the structures of $\mathrm{BE}, \mathrm{CE}$, and cocaine, the three compounds in each amphetamine class differ by the addition of a methyl or ethyl group. Between the three compounds in each class, the best separation was attained in helium. The best separation between the two classes was obtained in carbon dioxide. As discussed previously, the CCS value is a combination of the ion-neutral interaction and the ion/neutral sizes. For the amphetamines, it is suspected that the ions separate by size in helium, due to the minimal polarizability of helium. But the most important contributing factors can

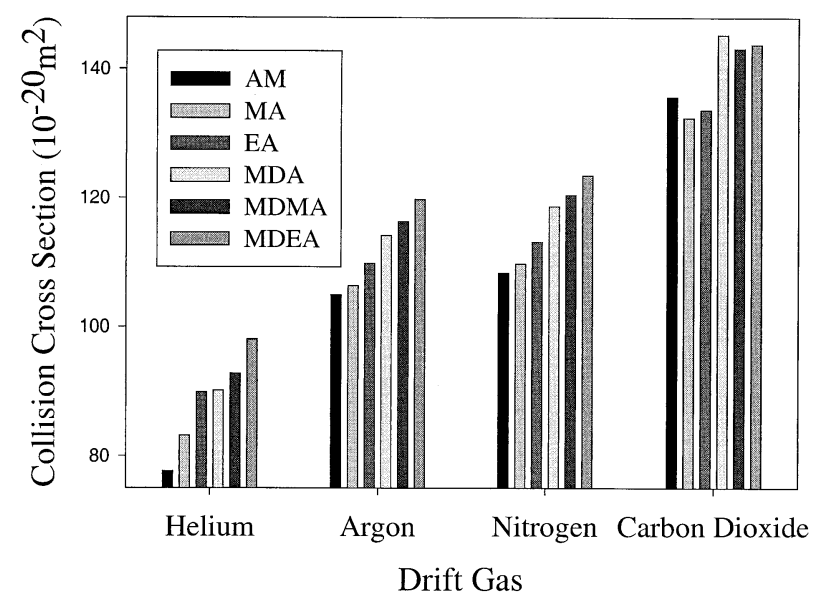

Figure 2. Comparison of calculated collision cross section values for six amphetamines in four different drift gases. 
Table 3. Table presents linear regression values obtained for collision cross section values against drift gas polarizability of six amphetamines in four different drift gases

\begin{tabular}{lccc}
\hline Amphetamine & Slope & y-Intercept & $\mathrm{R}^{2}$ \\
\hline \hline AM & 23.93 & 68.85 & 0.9712 \\
MA & 20.45 & 75.57 & 0.9737 \\
EA & 18.16 & 82.78 & 0.9686 \\
MDA & 22.67 & 81.25 & 0.9591 \\
MDMA & 20.92 & 85.08 & 0.9753 \\
MDEA & 19.06 & 91.08 & 0.9785 \\
\hline
\end{tabular}

Collision cross sections were calculated from experimental data according to Eq 3 and drift gas polarizability values are listed in Table 1

not be known precisely without a more rigorous approach to the data analysis.

In Table 3, the linear regression values for the six compounds are reported. In general, the slopes (i.e., degree of interaction with the drift gas) were greatest for the amphetamines (AM and MDA) and the least for the ethylamphetamines (EA and MDEA). The largest slope was obtained for AM and the smallest for EA. The $y$-intercepts increased with increasing mass except for EA and MDA (molecular weight difference of $16 \mathrm{a} \mu$ ).

\section{Drift Gas Selectivity}

Typically in IMS, experimental drift times are reported as $\mathrm{K}_{\mathrm{o}}$ values (see Eq 1). For comparison purposes between two compounds with known $\mathrm{K}_{\mathrm{o}}$ values, an IMS separation factor $(\alpha)$ can be reported as:

$$
\alpha=\mathrm{K}_{\mathrm{o} 1} / \mathrm{K}_{\mathrm{o} 2}
$$

where $\mathrm{K}_{\mathrm{o} 1}$ and $\mathrm{K}_{\mathrm{o} 2}$ are defined for the two compounds of interest. A separation factor of greater than 1 indicates that Compound 2 had a higher mobility (slower drift time) than Compound 1. This value is similar to the selectivity value defined in chromatography, however, for the separation factor defined here, the $\alpha$ value can be greater or less than 1 (in chromatography, the $\alpha$ value is always greater than 1).

From Eq 4 it is realized that a separation factor of 1 indicates that the two compounds cannot be separated with the current instrumental conditions. In Figure 3, the calculated separation factors for five benzodiazepines (based on measured $\mathrm{K}_{\mathrm{o}}$ values) are plotted in four drift gases (helium, argon, nitrogen, and carbon dioxide). There are two lines drawn across the plot in Figure 3 that correspond to separation factors of 1.02 and 0.98 . These two lines indicate that values greater than 1.02 and less than 0.98 would be separated from diazepam (defined as $\mathrm{K}_{\mathrm{o} 1}$ for this example). These upper and lower separation factor limits were calculated based on a baseline resolution for two peaks of 1.5 and typical instrumental resolving power of 125 [3e]. These two values will differ for each instrument and are dependent on the instrumental resolution achieved. Since $K_{o 1}$ was defined as the $K_{o}$ value for diazepam, all

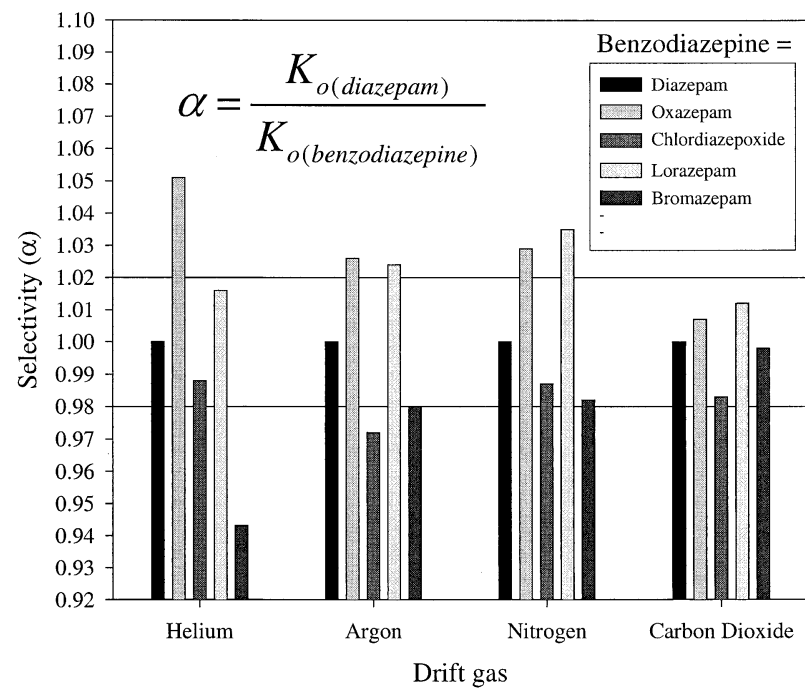

Figure 3. Plot of selectivity values for five benzodiazepines. Selectivity values less than 0.98 and greater than 1.02 indicate that the benzodiazepine could be separated from diazepam (calculation based on a $R_{p}$ of 125 and a baseline resolution value of 1.5). Graph shows that the selectivity for the benzodiazepines is specific to the drift gas and compound. Selectivity calculations were performed based on eq $x$ where $\mathrm{K}_{1}$ is $\mathrm{K}_{\text {diaz }}$ and $\mathrm{K}_{2}$ is $\mathrm{K}_{\text {benzo. }}$. All ions were the mass selected to be the $\mathrm{MH}^{+}$ions.

diazepam selectivity values were equal to one (see Figure 3). Comparison of the $\alpha$ values obtained for the other four benzodiazepines showed that all four compounds reach a separation value outside the limits (1.02 and 0.98), but the drift gas in which this occurs differed. For example, both lorazepam and oxazepam had $\alpha$ values greater than 1.02 in nitrogen and argon, indicating that these two compounds drifted slower than diazepam in these drift gases and thus, could be separated. In contrast, bromazepam could only be separated from diazepam in helium (separation factor of 0.94) and chlordiazepoxide could only be separated in argon. The trends in mobilities for drift gases were not apparent and this was thought to be due to the additional structural complexity for these five benzodiazepines. However, these results show the ability to predict separations based on literature $K_{o}$ values and the benefit of employing different drift gases to alter the selectivity and optimize the separation.

\section{Peptides}

For the past five years, significant advances have been made in the use of ESI/IMS coupled with mass spectrometry for biological compounds, specifically tryptic digests of proteins which result in the analysis of small peptide fragments [3d]. Extensive efforts have been made to ascertain peptide density, but only with helium as the drift gas. In the last section of this study, four peptides were evaluated; three with the $\mathrm{XK}$ formula (where $\mathrm{K}$ is lysine and $\mathrm{X}$ is glycine, valine, alanine, or methionine) and GHK (glycine-histidine-lysine). The first three were chosen to compare any differences 


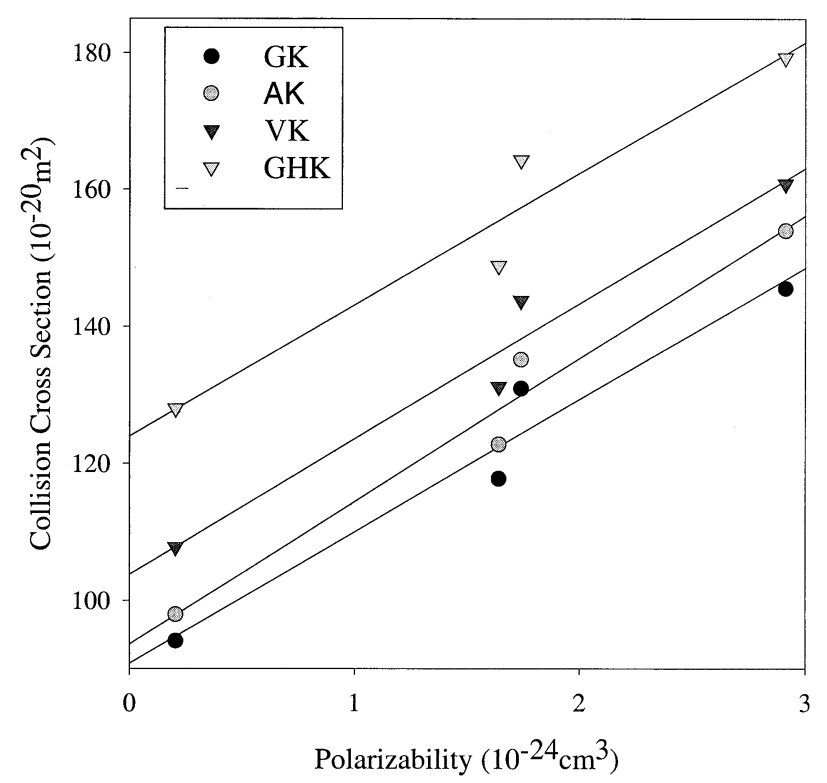

Figure 4. Graph shows the relationship between polarizability and collision cross section for four peptides, GK glycine-lysine, AK alanine-lysine, VK valine-lysine, and GHK glycine-histidinelysine. Error bars are smaller than the point size and are not visible on the graph.

observed due to the first amino acid group. Since protonation is expected to occur on the lysine group, any differences in the slopes and separation capabilities would be due to the variance in the other amino acid residue. The plots of the peptide CCS versus drift gas polarizability are shown in Figure 4. Inspection of Figure 4 showed that the general trends were the same for the four peptides with lysine as the terminal amino acid group. In all four peptides, there was an increase in collision cross section with polarizability. In Table 4, the linear regression values for the collision cross sections versus drift gas polarizability are presented. The yintercept increased with increasing molecular weight for the peptides (GK smallest and GHK largest).

\section{Database of $K_{o}$ Values}

In Table 5, the reduced mobility values were listed for all the compounds studied in each drift gas. This extends the mobility literature on several important classes of compounds (i.e., drugs and peptides) and

Table 4. Table presents linear regression values obtained for collision cross section values against drift gas polarizability of four peptides in four different drift gases

\begin{tabular}{lccc}
\hline Peptide & Slope & y-Intercept & $\mathrm{R}^{2}$ \\
\hline \hline GK & 19.27 & 90.76 & 0.9535 \\
AK & 20.85 & 93.56 & 0.9677 \\
VK & 19.75 & 103.8 & 0.9616 \\
GHK & 19.20 & 123.9 & 0.9366 \\
\hline
\end{tabular}

Collision cross sections were calculated from experimental data according to Eq 3 and drift gas polarizability values are listed in Table 1 enables the analyst to judiciously choose the best drift gas based on the $\mathrm{K}_{\mathrm{o}}$ values. Recently, our lab described a way to determine the resolution or separation efficiency required to separate two compounds based on the reduced mobility values for both compounds [3e]. With this database, an estimate of the resolution of the two compounds without the experimentation in each of the four drift gases can be made.

For example, based on work performed by Lawrence in the 1980's, the difficulty in separating many of the benzodiazepines was found [25]. In particular, the protonated ion of diazepam and the dehydrated lorazepam differed by only $0.005 \mathrm{~cm}^{2} \mathrm{~V}^{-1} \mathrm{~s}^{-1}$. Inspection of the reduced mobility value database in Table 5 showed that while similar mobility differences were found for nitrogen and argon, the mobility values had greater differences in both helium and carbon dioxide. The SIM spectra for these two ions in the four drift gases are shown in Figure 5. As suspected from the $\mathrm{K}_{\mathrm{o}}$ values, the two peaks were indistinguishable in both argon and nitrogen, but were easily separated in helium and carbon dioxide.

\section{Conclusions}

Prior to this study and that of Asbury, very little research had been dedicated to studying the utility of altering IMS separation factors by changing the drift gases. The work of Asbury and Hill showed that the drift gas (due to both the size and polarizability of the gas) could be utilized to change separation factors. The current study was carried out to evaluate the separation capabilities of IMS for several illicit drugs, metabolites and peptides in four different drift gases. Helium provided the best separation for similar compounds within the cocaine/metabolite mixture and the amphetamine mixture. Previous studies showed that generally the smallest ions have increased slopes. In contrast, the relative slopes for the amphetamine compounds were dependent on the amphetamine structure (simple versus methylene dioxy) and amine substitution. In all cases, one of the drift gases enabled separation of any two compounds, but the drift gas in which optimal separation was achieved was different for each compound pair. Drift gas composition programming $(100 \%$ carbon dioxide to $100 \%$ helium) could be a way to separate a mixture of compounds when the optimal drift gases differ.

\section{Acknowledgments}

The authors would like to acknowledge the funding contributions from the National Institutes of Health under Grant 8RO3DA1192302. Additional support was provided by the National Institutes of Health (National Institute of Drug Abuse division) for a scholarship awarded to LMM. 
Table 5. Database of reduced mobility values for drug and peptide compounds in four different drift gases

\begin{tabular}{|c|c|c|c|c|c|}
\hline Compound & Ion identity $(a \mu)$ & $\mathrm{K}_{\mathrm{o}}(\mathrm{He})^{\mathrm{a}}$ & $\mathrm{K}_{\mathrm{o}}(\mathrm{Ar})^{\mathrm{a}}$ & $\mathrm{K}_{\mathrm{o}}\left(\mathrm{N}_{2}\right)^{\mathrm{a}}$ & $\mathrm{K}_{\mathrm{o}}\left(\mathrm{CO}_{2}\right)^{\mathrm{a}}$ \\
\hline EME & $\mathrm{MH}^{+}(204)$ & 4.608 & 1.193 & 1.344 & 0.972 \\
\hline BE & $\mathrm{MH}^{+}(290)$ & 3.493 & 0.955 & 1.071 & 0.781 \\
\hline Cocaine & $\mathrm{MH}^{+}(304)$ & 3.382 & 0.933 & 1.063 & 0.780 \\
\hline CE & $\mathrm{MH}^{+}(318)$ & 3.199 & 0.912 & 1.028 & 0.762 \\
\hline EME & $(\mathrm{M}+\mathrm{Na})^{+}(226)$ & - & 1.128 & 1.300 & 0.948 \\
\hline $\mathrm{BE}$ & $(\mathrm{M}+\mathrm{Na})^{+}(312)$ & - & 0.926 & 1.029 & 0.730 \\
\hline Cocaine & $(\mathrm{M}+\mathrm{Na})^{+}(326)$ & - & 0.916 & 1.042 & 0.754 \\
\hline CE & $(\mathrm{M}+\mathrm{Na})^{+}(340)$ & - & 0.895 & 1.006 & 0.734 \\
\hline AM & $\mathrm{MH}^{+}(136)$ & 5.370 & 1.393 & 1.557 & 1.037 \\
\hline MA & $\mathrm{MH}^{+}(150)$ & 5.001 & 1.359 & 1.524 & 1.050 \\
\hline EA & $\mathrm{MH}^{+}(164)$ & 4.619 & 1.304 & 1.469 & 1.030 \\
\hline MDA & $\mathrm{MH}^{+}(180)$ & 4.599 & 1.243 & 1.390 & 0.939 \\
\hline MDMA & $\mathrm{MH}^{+}(194)$ & 4.464 & 1.211 & 1.363 & 0.946 \\
\hline MDEA & $\mathrm{MH}^{+}(208)$ & 4.217 & 1.170 & 1.323 & 0.936 \\
\hline Diazepam & $\mathrm{MH}^{+}(284)$ & 3.546 & 0.993 & 1.123 & 0.815 \\
\hline \multirow[t]{2}{*}{ Oxazepam } & $\left(\mathrm{M}-\mathrm{H}_{2} \mathrm{O}\right) \mathrm{H}^{+}(268)$ & 3.803 & 1.058 & 1.184 & 0.856 \\
\hline & $\mathrm{MH}^{+}(286)$ & 3.588 & 1.022 & 1.138 & 0.829 \\
\hline Chlordiaz. & $\mathrm{MH}^{+}(300)$ & 3.374 & 0.968 & 1.091 & 0.809 \\
\hline \multirow[t]{2}{*}{ Lorazepam } & $\left(\mathrm{M}-\mathrm{H}_{2} \mathrm{O}\right) \mathrm{H}^{+}(302)$ & 3.673 & 1.001 & 1.118 & 0.841 \\
\hline & $\mathrm{MH}^{+}(320)$ & 3.491 & 0.970 & 1.085 & 0.805 \\
\hline Bromaz. & $\mathrm{MH}^{+}(316)$ & 3.761 & 1.013 & 1.144 & 0.817 \\
\hline GK & $\mathrm{MH}^{+}(204)$ & 4.340 & 1.187 & 1.245 & 0.923 \\
\hline$A K$ & $\mathrm{MH}^{+}(218)$ & 4.165 & 1.133 & 1.201 & 0.868 \\
\hline VK & $\mathrm{MH}^{+}(278)$ & 3.647 & 0.978 & 1.077 & 0.798 \\
\hline GHK & $\mathrm{MH}^{+}(341)$ & 3.308 & 1.003 & 1.011 & 0.753 \\
\hline
\end{tabular}

${ }^{\mathrm{a}} \mathrm{K}_{\mathrm{o}}$ values are in $\mathrm{cm}^{2} \mathrm{~V}^{-1} \mathrm{~s}^{-1}$.
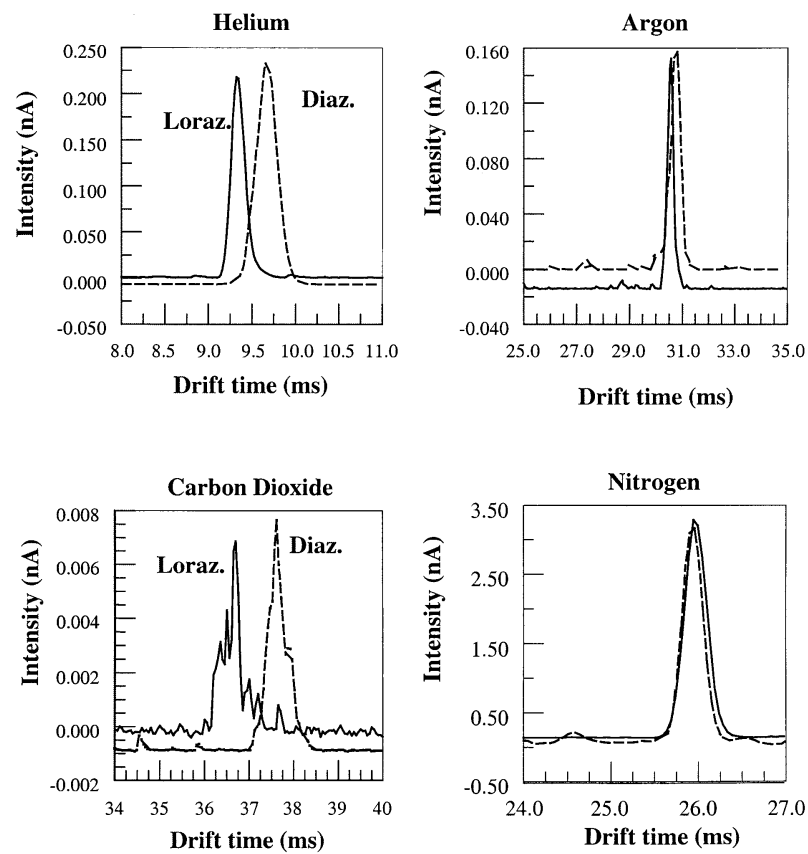

Figure 5. Comparison of two benzodiazepines in the four different drift gases, lorazepam and diazepam. Ions were mass-identified as follows: Diazepam $(\mathrm{MH})^{+}$and lorazepam $\left(\mathrm{M}-\mathrm{H}_{2} \mathrm{O}\right) \mathrm{H}^{+}$. Graph shows that by changing the drift gas, the separation of two ions can be altered. Previous IMS results in both nitrogen and air have shown the difficulty in separating these two ions.

\section{References}

1. (a) ESI/IMS; Geinec, J.; Mack, L. L.; Nakamae, K.; Gupta, C.; Kumar, V.; Dole, M. Electrospray Mass Spectrometry of Macromolecules: Application of an Ion-Drift Spectrometer. Biomedical Mass Spectrometry 1984, 11, 259. (b) Shumate, C. B.; Hill, H. H., Jr. Coronaspray Nebulization and Ionization of Liquid Samples for Ion Mobility Spectrometry. Anal. Chem. 1989, 61, 601. (c) Smith, R. D.; Loo, J. A.; Ogorzalek, R. R.; Busman, M. Principles and Practice of Electrospray Ionization-Mass Spectrometry for Large Polypeptides and Proteins. Mass Spectrom. Rev. 1991, 10, 359-451. (d) Wittmer, D. H.; Chen, Y. H.; Luckenbill, B. K.; Hill, H. H., Jr. Electrospray Ionization Ion Mobility Spectrometry. Anal. Chem. 1994, 66, 2348.

2. Gillig, K. J.; Ruotolo, B.; Stone, E. G.; Russell, D. H.; Fuhrer, K.; Gonin, M.; Schultz, A. J. Coupling High Pressure MALDI with Ion Mobility/Orthogonal Time of Flight Mass Spectrometry. Anal. Chem. 2000, 72, 3965.

3. (a) High-Resolution IMS: Wu, C.; Siems, W. F.; Rasulev, U. K.; Nazarov, E. G.; Hill, H. H., Jr. Mass Identification of Mobility Separated Ions formed by Electrospray Ionization and Surface Ionization. Proceedings of the 45th ASMS Conference on Mass Spectrometry and Allied Topics; Palm Springs, CA, June 1997; p 376. (b) Dugourd, P. H.; Hudgins, R. R.; Clemmer, D. E.; Jarrold, M. F. High-Resolution Ion Mobility Measurements. Rev. Sci. Instrum. 1997, 68, 1122. (c) Wu, C.; Siems, W. F.; Asbury, G. R.; Hill, H. H., Jr. Electrospray Ionization HighResolution Ion Mobility Spectrometry-Mass Spectrometry. Anal. Chem. 1998, 70, 4929. (d) Srebalus, C. A.; Li, J.; Marshall, W. S.; Clemmer, D. E. Gas Phase Separations of Electrosprayed Peptide Libraries. Anal. Chem. 1999, 71, 3918. (e) Asbury, G. R.; Hill, H. H., Jr. Evaluation of High Resolution Ion Mobility Spectrometry as an Analytical Separation Device in Chromatographic Terms. J. Microcol. Sep. 2000, 12, 172. 
4. Wu, C.; Siems, W. F.; Hill, H. H., Jr. Secondary Electrospray Ionization Ion Mobility Spectrometry/Mass Spectrometry of Illicit Drugs. Anal. Chem. 2000, 72, 396-403.

5. Asbury, G. R.; Wu, C.; Siems, W. F.; Hill, H. H., Jr. Separation and Identification of Some Chemical Warfare Degradation Products Using Electrospray High Resolution Ion Mobility Spectrometry with Mass Selected Detection. Anal. Chim. Acta 2000, 404, 273-283.

6. Wu, C.; Klasmeier, J.; Hill, H. H., Jr. Atmospheric Pressure Ion Mobility Spectrometry of Protonated and Sodiated Peptides. Rapid Commun. Mass Spectrom. 1999, 13, 1138-1142.

7. (a) For Reviews see: Clemmer, D. E.; Jarrold, M. F. Ion Mobility Measurements and their Applications to Clusters and Biomolecules. J. Mass Spectrom. 1997, 32, 577-592. (b) Hoaglund-Hyzer, C. S.; Counterman, A. E.; Clemmer, D. E. Anhydrous Protein Ions. Chem. Rev. 1999, 99, 3037-3079.

8. St. Louis, R. H.; Hill, H. H., Jr. Ion Mobility Spectrometry in Analytical Chemistry. Crit. Rev. Anal. Chem. 1990, 21, 321-355.

9. Purves, R. W.; Guevremont, R. Electrospray Ionization HighField Asymmetric Waveform Ion Mobility Spectrometry-Mass Spectrometry. Anal. Chem. 1999, 71, 2346-2357.

10. Eiceman, G. A.; Karpas, Z. Ion Mobility Spectrometry. CRC Press: Boca Raton, FL, 1994 pp 145-164.

11. Revercomb, H. E.; Mason, E. A. Theory of Plasma Chromatography/Gaseous Electrophoresis-A Review. Anal. Chem. 1975, 47, 970-983.

12. Ellis, H. W.; Pai, R. Y.; Gatland, I. R.; McDaniel, E. W.; Wernlund, R.; Cohen, M. J. Ion Identity and Transport Properties in Carbon Dioxide Over a Wide Pressure Range. Anal. Chem. 1976, 64, 3935-3941.

13. Berant, Z.; Karpas, Z.; Shahal, O. Effects of Temperature and Clustering on Mobility of Ions in Carbon Dioxide. J. Phys. Chem. 1989, 93, 7529-7532.

14. Rokushika, S.; Hatano, H.; Hill, H. H., Jr. Ion Mobility Spectrometry in Carbon Dioxide. Anal. Chem. 1986, 58, 361-365.

15. Carr, T. W. Comparison of the Negative Reactant Ions Formed in the Plasma Chromatograph by Nitrogen, Air, and Sulfur
Hexafluoride as the Drift Gas with Air as the Carrier Gas. Anal. Chem. 1979, 51, 705-711.

16. Sennhauser, E. S.; Armstrong, D. A. Ion Mobilities in Gaseous Ammonia. Can. J. Chem. 1978, 56, 2337-2341.

17. Yamashita, T.; Kobayashi, H.; Konaka, A.; Kurashige, H.; Miyake, K.; Morii, M. M.; Nakamura, T. T.; Nomura, T.; Sasao, N.; Fukushima, Y.; Nomachi, M.; Sasaki, O.; Suekane, F.; Taniguchi, T. Measurements of the Electron Drift Velocity and Positive-Ion Mobility for Gases Containing $\mathrm{CF}_{4}$. New Instrum. Methods Phys. Res. 1989, A283, 709-715.

18. Mesleh, M. F.; Hunter, J. M.; Shvartsburg, A. A.; Schatz, G. C.; Jarrold, M. F. Structural Information from Ion Mobility Measurements: Effects of the Long Range Potential. J. Phys. Chem. 1996, 100, 16082.

19. Shvartsburg, A. A.; Jarrold, M. F. An Exact Hard Spheres Scattering Model for the Mobilities of Polyatomic Ions. Chem. Phys. Lett. 1996, 261, 86.

20. Shvartsburg, A. A.; Mashkevich, S. V.; Siu, K. W. M. Incorporation of Thermal Rotation of Drifting Ions into Mobility Calculations: Drastic Effect for Heavier Ions. J. Phys. Chem. A 2000, 104, 9448.

21. Sennhauser, E. S.; Armstrong, D. A. Ion Mobilities and Collision Frequencies in Gaseous $\mathrm{CH}_{3} \mathrm{Cl}, \mathrm{HCl}, \mathrm{HBr}, \mathrm{H}_{2} \mathrm{~S}, \mathrm{NO}$, and $\mathrm{SF}_{6}$ : Effects of Polarity of the Gas Molecules. Can. J. Chem. 1980, 58, 231-237.

22. Karpas, Z.; Berant, Z. Effect of Drift Gas on Mobility of Ions. J. Phys. Chem. 1989, 93, 3021-3025.

23. Asbury, G. R.; Hill, H. H., Jr. Using Different Drift Gases to Change Separation Factors in Ion Mobility Spectrometry. Anal. Chem. 2000, 72, 580-584.

24. Beegle, L. W.; Kanik, I.; Matz, L.; Hill, H. H., Jr. Electrospray Ionization/Ion Mobility Spectrometry for the Detection of Organic Compounds. Anal. Chem. 2001, 73, 3028.

25. Lawrence, A. H. Ion Mobility Spectrometry/Mass Spectrometry of Some Prescription and Illicit Drugs. Anal. Chem. 1989, 61,601 . 